\title{
Aqua Solar Canopy-A Model based on Rainwater Harvesting and Solar Energy Production
}

\author{
Bhavya Bansal
}

\begin{abstract}
Scarcity of water is a major existing problem in India. Of all the water available to us, only $3 \%$ is pure and usable, and with more than 7 billion people on earth. Rainwater is the most undervalued of the types of freshwater available. Rainwater harvesting is one of the oldest and simplest method for saving and using water. It can be used for residential and household projects, and even larger systems for schools, hospitals and other facilities. Considering the scarcity of water in our country, lesser use of rain water and depleting renewable sources of energy, this model was developed to make it useful for masses and at a affordable price.
\end{abstract}

Keywords: Aqua (Water); Rainwater Harvesting; Solar Energy; Canopy

\section{I.INTRODUCTION}

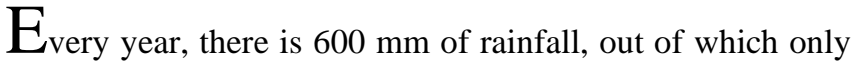
$2 \mathrm{~mm}$ get harvested, which is a very small amount. Times of India states that every monsoon, about 468 billion liters of water gets wasted. According to facts, on average, every cubic meter of earth surface receives around $990 \mathrm{~mm}$ of rainfall yearly, and with a house of an average area of $100 \mathrm{~m}^{2}$, one would be able to conserve approximately 100 , $000 \mathrm{~L}$ of water yearly. If non- renewable resources are used to produce electricity at such a fast pace, they will get finished in the near future. Therefore it's time to switch to renewable resources to produce electricity. Rainwater harvesting provides the independent water supply during regional water restrictions, and in developed countries, it is often used to supplement the main supply. India, being near the equator, receives a large amount of solar energy throughout the year. Thus using solar energy for generating electricity can be an excellent idea. By producing solar energy, India will be able to produce a larger amount of clean energy which would be affordable for the masses. ${ }^{1}$

\section{II.MATERIAL AND METHODS}

Principle: Aqua-Solar Canopy performs numerous functions. Aqua- As the name suggests, it's the main function to use rainwater i.e., rainwater harvesting. This model has a big metallic canopy.

Manuscript received on October 11, 2021.

Revised Manuscript received on October 16, 2021.

Manuscript published on October 30, 2021.

* Correspondence Author

Bhavya Bansal*, Student, Sat Paul Mittal School, Ludhiana, Punjab, India. E-mail: bbansal5600@gmail.com

(C) The Authors. Published by Blue Eyes Intelligence Engineering and Sciences Publication (BEIESP). This is an open access article under the CC BY-NC-ND license (http://creativecommons.org/licenses/by-nc-nd/4.0/)
This canopy can be made in larger size to be placed on the roof of the house, it would collect all the rainwater received by your house. Then via a long pipe, the rainwater is distributed into 2 chambers. 1st chamber consists of a natural water purifier made of charcoal, sand, gravel, and filter paper. Via this filter, the rainwater entering this chamber gets devoid of all the wastes and impurities. After purification, this water gets stored in the house water tank for various household purposes. The second chamber is actually a plain long tube that finally reaches a tank that stores water for irrigation of plants. Solar- As the name suggests, this canopy contains few solar panels that would charge the battery. This battery would store the electricity. After storage, this electricity can be used for running lights and fans as and when required. This project clearly demonstrates how the energy is produced, how it charges the battery, and how the battery helps in running the LED lights. The LED lights are connected to an LDR sensor. Because of this, when the atmospheric lighting is less than adequate, the LED lights turn on whereas when the atmospheric lighting is enough, the LED lights turn off. The circuit is also provided with an additional switch to manually control it. This entire procedure helps in energy conservation. $^{2}$ Aqua-Solar canopy is a prototype. This prototype is completely functional and performs all the tasks of the actual canopy (Figure 1 and Figure 2)

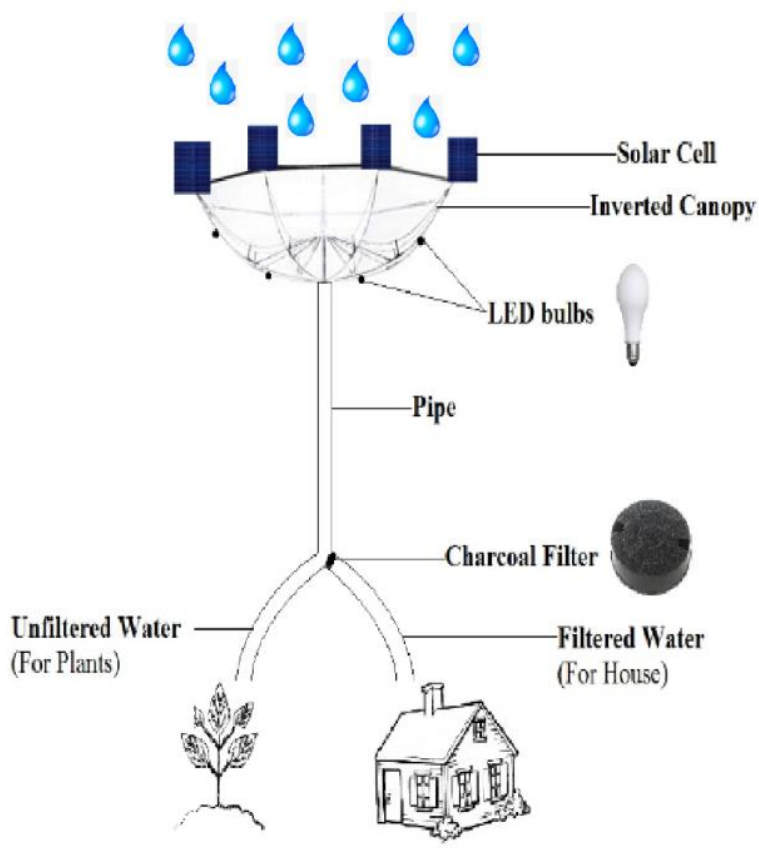

Figure 1- Aqua Solar Canopy- Prototype

Published By:

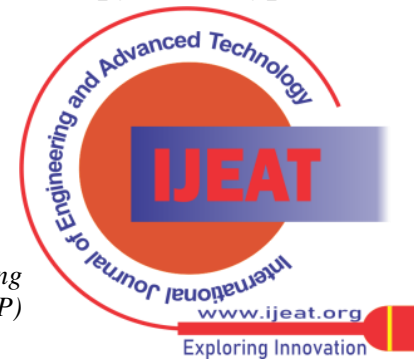




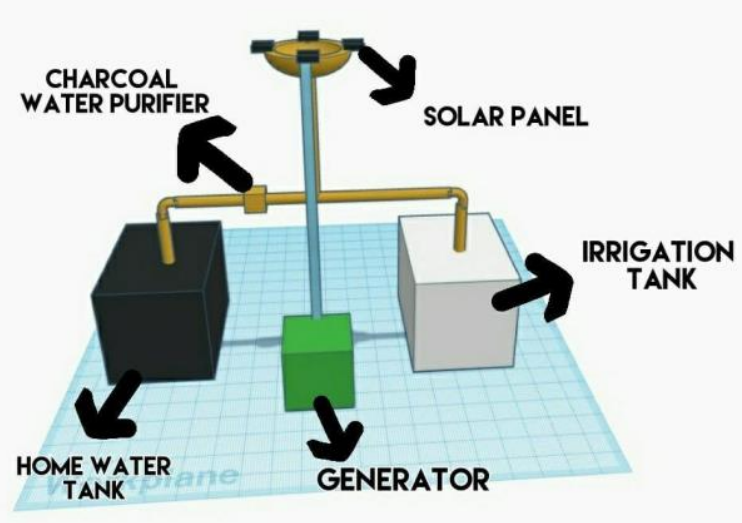

Figure 2- Aqua Solar Canopy- 3D Model

\section{A. Objective of my project}

1. To purify and filter rainwater by passing it through activated charcoal, sand and gravel.

2. To produce electricity with the help of solar panels.

\section{B. Online Survey}

Before developing my actual model and to understand the knowledge and awareness of general public regarding rainwater harvesting, hydro and solar energy, a survey was conducted designing a Google form questionnaire consisting of ten questions and circulated it to various rural and urban people. This questionnaire had questions regarding their knowledge regarding rainwater harvesting, its potential benefits, whether it shall be used on large scale or not and people would like to accept it or not. Being influenced by its benefits and impressed by people's interest in this concept, it was planned to make this solar canopy project. The questionnaire was circulated to 233 people. 91\% people responded that they were aware regarding rain water harvesting but haven't used ever, though $8.1 \%$ people weren't aware about this concept. 98\% people responded positively that they would like to use this kind of projects at their farms, houses and fields if they get cost effective model. 65\% people responded positively to fund this project to make it at large scale. To begin with, a canopy was made up of copper, then a durable structure of iron was used after welding as a stand, and got it welded to make it strong enough to uphold the force applied by falling water. Water purifying system, using charcoal, sand, gravel, and filter paper was added. Two pipes were connected, one for filtering the rainwater for household use and another pipe directly for plants and vegetation. Along with this, electricity generation via solar panels fitted at the top (roof side) of the canopy and the automatic lighting system using an LDR sensor for lightening the house was also added.

\section{Cost of the project}

India is a developing country and majority of our population stays in villages. Therefore it was planned to make a project which is cost effective and can be used by masses. This model (prototype) was made a cost effective model which is easily affordable for its users. It has low cost with low maintenance. The canopy made up of copper cost around Rupees 800 and the iron rods used in the product cost Rupees 200 altogether. The welding was done for Rupees 100 , and the solar panels, led lights were reused from previous projects. The activated charcoal was for rupees 40 . Therefore, the total cost of the product came out to be around rupees 1400 . Rest all things were reused from previous projects. The product is very beneficial for the environment. I completely avoided the use of plastics.

\section{III.RESULTS}

Aqua solar canopy is an efficiently working model and cost effective. Though it is a prototype, it is completely functional. Besides, the prototype is in proper functioning condition. The solar panels of the prototype generate $8 \mathrm{~V}$ of electricity per hour which is sufficient for charging a $9 \mathrm{~V}$ battery and operating the LED lights and an LDR sensor. The filter is tested and removes $95 \%$ of the suspended impurities present in the rainwater.

\section{IV.FUNCTION AND SCIENTIFIC CONCEPT USED}

The primary function of this Aqua Solar Canopy is to collect the rainwater and filter and purify this water and use it for household purposes. This rainwater can also be used in watering plants. The rod connected with canopy is made up of steel which is strong and ductile. First, this rainwater gets collected in a canopy made up of copper which is a natural coolant and is used to cool the rainwater. Then this rainwater passes through some natural filters like activated charcoal, sand, gravel, etc. Then this purified water gets stored in a tank and is ready to use. Unfiltered water from other pipe can be used for watering plants. The other function of this aqua-solar canopy is to produce electricity. For producing the electricity we have installed 4 solar panels (which are water-resistant) at its corners. This production of electricity is demonstrated with the help of glowing bulbs. The lights glow according to the lighting of the surroundings, i.e. they will glow only if there is no light in the surroundings. Aqua-Solar Canopy uses the concept of electricity generation via solar panels. When solar energy falls on the surface of the solar panels, free electrons are released which on being connected to a battery, generates electrical energy for charging the battery. ${ }^{1,2}$ The battery is then connected to an automatic lighting circuit via an LDR sensor.

\section{A. Novel Features Of The Project}

It is a multipurpose device using principle of rain-water harvesting to provide filtered clean water to people and unfiltered water for crops. Large canopy shaped copper metal, with solar panels, can be placed at roofs of houses or buildings suggesting best space utilization, having solar panels making it a source of solar energy, producing electricity, a cost effective, a model useful for masses and developed by a student.

\section{B. Advantages}

There are various advantages of this equipment. First and foremost advantage is that it can help solving the problem of water scarcity in our country.

Published By:

Blue Eyes Intelligence Engineering

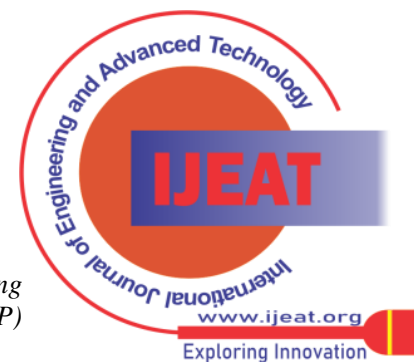


More and more people can get filtered water for drinking, domiciliary use as well as for large scale industries. The unfiltered water can be used for irrigation; it will promote planting more trees and plants at homes and surroundings, helping in reducing air pollution. The other major advantage of our project is use of solar panels creating solar energy, an important renewable source of energy which can be converted into electrical energy, used for lighting the houses and buildings and giving an affordable energy for our country. LED sensors serve the purpose of not wasting energy, as whenever there is natural light, the bulbs will get off automatically.

\section{CONCLUSION}

To conclude, this project can be very useful if used at a larger scale. It is a useful tool to save water and electricity. We need to use renewable sources of energy, as much as possible to reduce pollution and avoid climate change. These kinds of big metal canopies can be fitted at the roofs of houses and buildings to serve the dual purpose.

\section{FUTURE POTENTIAL OF THE PROJECT}

Presently my project is a prototype of rainwater harvesting with solar energy, which is in workable condition. As my project is very cost-effective and efficiently working, I am sure that it can be used at the mass level at a low cost. It shall be very useful at the community level in our country. The product can be used on a large scale, to purify water for drinking purposes; the filter can be of better quality and of greater efficiency. An automatic irrigation system can be installed using a humidity sensor to reduce the wastage of water. The product can be commercialized. Such kind of devices can be installed in public parks, educational institutions, big societies and individual homes as well.

\section{ACKNOWLEDGEMENT}

I would like to acknowledge my parents for supporting me in this concept and Ms. Jasmit Janeja (Science Teacher) for guiding me.

\section{REFERENCES}

1. Ehsanul Kabir, Pawan Kumar, Sandeep Kumar et al. Solar energy: potential and Future Prospects. Renewable and Sustainable Energy Reviews. 82 (2018) 894- 900.

2. Mohd Rizwan Sirajuddin Shaikh, Santosh B. Waghmare, Suvarna Shankar Labade, Pooja Vittal Fuke et al. A Review Paper on Electricity Generation from Solar Energy. IJRASET. 5(2017) 18841888.

\section{AUTHORS PROFILE}

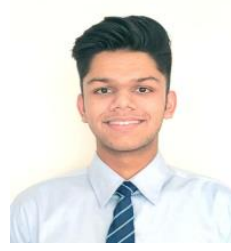

Bhavya Bansal, Student Grade 10, Sat Paul Mittal School, Ludhiana, Punjab, 141012 Bhavya is an India Book of Record Holder in 2019 for being youngest in making a multipurpose Dream Machine. He was $1^{\text {st }}$ runner up at World Education Robotics Championship, at Shanghai, China, in 2016 and $2^{\text {nd }}$ runner up at International Robotronics Championship at Dubai, UAE, in 2017. Bhavya has authored publication "Role of Artificial Intelligence in Medicine during COVID-19 virus Pandemic" in IRJET.

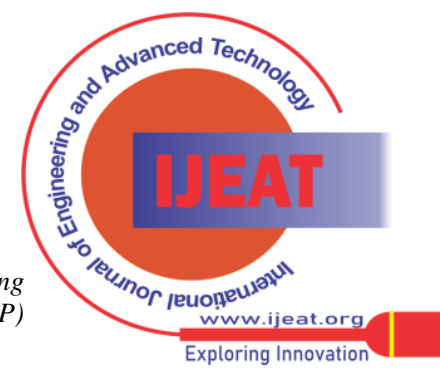

